University of Nebraska - Lincoln

DigitalCommons@University of Nebraska - Lincoln

7-1-2001

\title{
Ferromagnetic Co-C nanodot arrays produced by direct interferometric laser annealing
}

\author{
M. Zheng \\ University of Nebraska - Lincoln \\ M. Yu \\ University of Nebraska - Lincoln \\ Yi Liu \\ University of Nebraska-Lincoln, yliu@unl.edu \\ Ralph Skomski \\ University of Nebraska-Lincoln, rskomski2@unl.edu \\ David J. Sellmyer \\ University of Nebraska-Lincoln, dsellmyer@unl.edu \\ See next page for additional authors
}

Follow this and additional works at: https://digitalcommons.unl.edu/physicsliou

Part of the Physics Commons

Zheng, M.; Yu, M.; Liu, Yi; Skomski, Ralph; Sellmyer, David J.; Petryakov, V.N.; Verevkin, Yu. K.; Polushkin, Nikolay; and Salashchenko, N.N., "Ferromagnetic Co-C nanodot arrays produced by direct interferometric laser annealing" (2001). Si-Hwang Liou Publications. 86.

https://digitalcommons.unl.edu/physicsliou/86

This Article is brought to you for free and open access by the Research Papers in Physics and Astronomy at DigitalCommons@University of Nebraska - Lincoln. It has been accepted for inclusion in Si-Hwang Liou Publications by an authorized administrator of DigitalCommons@University of Nebraska - Lincoln. 


\section{Authors}

M. Zheng, M. Yu, Yi Liu, Ralph Skomski, David J. Sellmyer, V.N. Petryakov, Yu. K. Verevkin, Nikolay Polushkin, and N.N. Salashchenko 


\title{
Ferromagnetic Co-C Nanodot Arrays Produced by Direct Interferometric Laser Annealing
}

\author{
M. Zheng, M. Yu, Y. Liu, R. Skomski, S. H. Liou, D. J. Sellmyer, V. N. Petryakov, Yu. K. Verevkin, N. I. Polushkin, \\ and N. N. Salashchenko
}

\begin{abstract}
Magnetic properties of Co-C nanodot arrays produced by direct interferometric laser annealing are investigated by magnetic force microscopy (MFM) and magnetization measurements. The dots are formed by locally annealing sputtered amorphous $\mathrm{Co}-\mathrm{C}$ films in regions where the laser intensity is highest. As-sputtered $\mathrm{Co}-\mathrm{C}$ films do not exhibit ferromagnetic order at room temperature, but MFM shows that the dots become magnetic upon annealing, possibly due to the agglomeration or phase separation of Co-rich clusters. The dots are embedded in either a paramagnetic or weakly magnetic matrix. The magnetic properties of the generated pattern can be changed by varying the laser power. The present results show that direct interferometric lithography may become a useful tool for fabricating future patterned magnetic nanostructures.
\end{abstract}

Index Terms-Artificially structured materials-small particles and patterned films, magnetic domains.

\section{INTRODUCTION}

C ONVENTIONAL photolithography has been widely used to pattern large-area devices, used for example in semiconductor industry to manufacture integrated circuit. In recent years, several groups have demonstrated that interferometric lithography is a rapid and economical way to generate large area dot arrays with periods of a few hundreds nanometers [1]-[3]. This is of interest in magnetic storage technology, where much attention has to be paid on simple, economic and time-saving procedures, and where cleanliness and smoothness are essential criteria [4].

Conventional photolithography is a multi-step process, involving the cumbersome process of appyling resist, etching and subsequent cleaning, which complicates the fabrication of patterned magnetic media. Our recent work has shown that it is viable to employ interferometric laser to generate magnetic nanodot arrays directly [5]. The dots are formed by locally annealing the sputtered amorphous $\mathrm{Co}-\mathrm{C}$ films in regions where the laser intensity is highest. Co-C films were chosen because

Manuscript received October 13, 2000.

This work was supported by NSF, CMRA, the Nebraska Research Initiative and the Russian Foundation of Basic Research (RFBR, \#01-02-16445). The work of S. H. Liou was supported by Army Research Office, Grant DAAD 19-00-1-0119.

M. Zheng, M. Yu, Y. Liu, R. Skomski, S. H. Liou, and D. J. Sellmyer are with the Center for Materials Research and Analysis and Department of Physics and Astronomy, University of Nebraska, Lincoln, NE 68588 (e-mail: mzheng2@unl.edu).

V. N. Petryakov and Yu. K. Verevkin are with the Institute of Applied Physics of RAS, 603600 Nizhni Novgorod, Russia.

N. I. Polushkin and N. N. Salashchenko are with the Institute for Physics of Microstructures of RAS, 603600 GSP-105, Nizhni Novgorod, Russia.

Publisher Item Identifier S 0018-9464(01)06173-8.

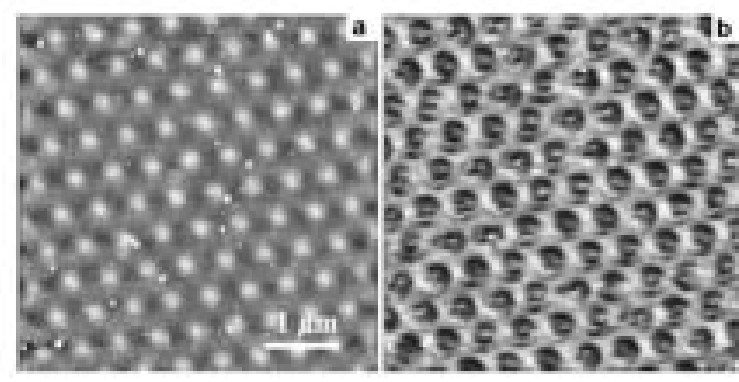

Fig. 1. AFM image (a) and MFM image (b) of a patterned Co-C film.

the metastable Co carbides decompose easily into Co and C upon annealing and form a simple system with immiscible magnetic and nonmagnetic phases [6]-[9]. In this paper, we use magnetic force microscopy (MFM) and magnetization measurements to study the formed magnetic nanodots and the relation between the dot formation and applied laser power.

\section{EXPERMENTS}

The $\mathrm{Co}_{50} \mathrm{C}_{50}(\mathrm{at} \%)$ films studied in this work were co-sputtered onto a water-cooled 7059 glass substrate with a thickness of $20 \mathrm{~nm}$. Then the sputtered films were exposed to a 10-ns pulsed excimer laser having a wavelength of $308 \mathrm{~nm}$ and a flux of $0.24 \mathrm{~J} / \mathrm{cm}^{2}$. The laser beam was split into two beams of an approximately equal intensity and then recombined, generating an interference pattern and a periodic modulation of the light intensity. The size and shape of the regions depend on the incident angles of the beam, pulse duration, and flux.

Topography and microstructure were carried out by atomic force microscopy (AFM). Magnetic properties of as-sputtered and patterned Co-C films were examined using a super-conducting quantum interference device (SQUID) magnetometer and MFM. MFM images are frequency images acquired by a high-coercivity CoPt tip magnetized along the tip direction, that is, perpendicular to the film plane.

\section{RESULTS AND DISCUSSION}

Fig. 1 shows (a) the AFM image and (b) the MFM image of a patterned Co-C film. The MFM image was obtained by a low stray field MFM tip. The dots have a diameter of about $250 \mathrm{~nm}$ and a center-to-center spacing of about $375 \times 750 \mathrm{~nm}$. The center of the dots has a height of $10 \mathrm{~nm}$. The observed topographical contrast from AFM picture basically reflects the surface lifting 


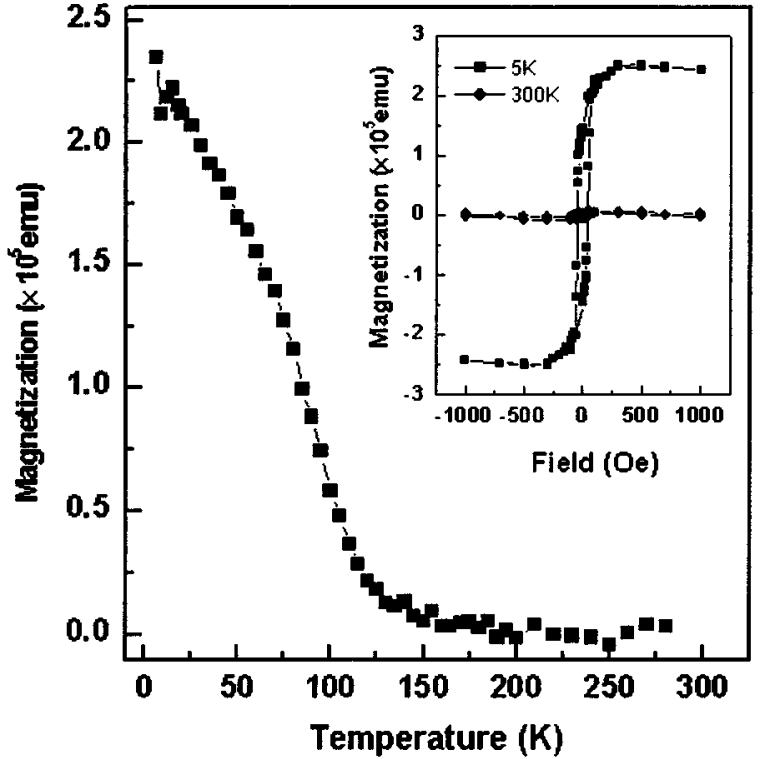

Fig. 2. Temperature dependence of the magnetization of the as-sputtered Co-C film measured at 100 Oe by SQUID. The hysteresis loops at $5 \mathrm{~K}$ and $300 \mathrm{~K}$ are shown as inset.

in interference maxima by phase changes in carbon [5]. The MFM image shows that the dots are magnetic and embedded in a nonmagnetic matrix and multi-domain structures were observed within each dot.

Fig. 2 shows the temperature dependence of the magnetization of the as-sputtered Co-C film at 100 Oe. The hysteresis loops at $5 \mathrm{~K}$ and $300 \mathrm{~K}$ are shown as inset. The as-sputtered film exhibits a ferromagnetic hysteresis loop at low temperatures, but the collapse of the magnetization far below the Curie temperature of Co $(1388 \mathrm{~K})$ indicates that this hysteresis is due to very small superparamagnetic Co particles. After laser patterning, magnetic hysteresis is observed at $5 \mathrm{~K}$ and $300 \mathrm{~K}$ [5], and in both cases the coercivity is of the order of $100 \mathrm{Oe}$.

The dot formation and ferromagnetic order at room temperature are attributed to the agglomeration or phase separation of as-sputtered Co-C film upon local annealing at laser intensity maxima [5]. A recent study on a similar $\mathrm{Fe}-\mathrm{C}$ nanocomposite films [10] revealed $\mathrm{Fe}$ and $\mathrm{C}$ phase separation even in the as-sputtered samples characterized by an average in-plane grain diameter of about $2 \mathrm{~nm}$ embedded in a graphitized $\mathrm{C}$ matrix. Those Fe-C films exhibit superparamagnetic behavior with blocking temperature in the range of 13-180 K [10]. Similarly, as-sputtered $\mathrm{Co}-\mathrm{C}$ films may contain tiny superparamagnetic Co or Co-rich clusters. The Co atoms re-arrange upon laser annealing and form more strongly interacting magnetic Co or Co-rich clusters which yield the observed magnetic phase at room temperature.

The formed dots can be embedded either in paramagnetic matrix as shown above or in weak magnetic matrix. Fig. 3 shows a MFM image of the patterned Co-C film under higher laser power. A $180^{\circ}$-domain wall was observed, as evidenced by the reversed black-white contrast of the dipole-like shape of the dots. The domain pattern indicates the presence of interdot exchange interaction via the ferromagnetic matrix. Spin-glass type

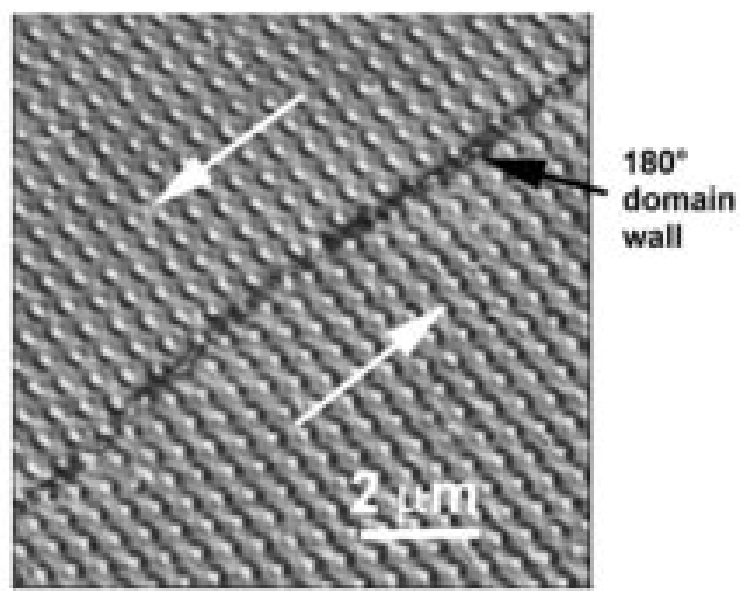

Fig. 3. MFM image of the patterned Co-C film under higher laser power.

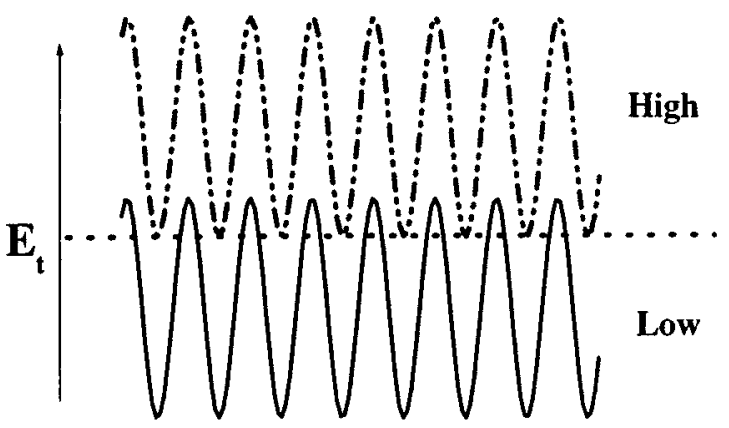

High Laser Power

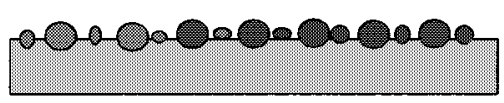

Low Laser Power

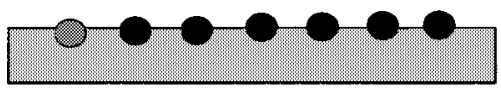

Fig. 4. Schematic view of pattern formation by interferometric laser annealing process under moderate and high laser power.

RKKY and magnetostatic dipole interactions are likely to exist but cannot explain the pattern shown in Fig. 3 .

The reason for the induced ferromagnetic character of the matrix is most likely due to the comparatively high laser intensity. Fig. 4 illustrates the pattern formation by interferometric laser annealing. Suppose there is a threshold value of laser power, $E_{t}$. Only when the laser intensity is higher than $E_{t}$ can the film be made magnetic due to the Co atoms re-arrangement or phase separation upon annealing. At moderate laser power, e.g., Fig. 1, only dot regions formed under the laser intensity maxima whose power is higher than the threshold become magnetic while matrix under the laser intensity minima remains paramagnetic. If employed laser power is too high, the intensity of the laser minima has already been higher than $E_{t}$ so that 
both dots and inter-dot regions become ferromagnetic, which is seen in Fig. 3.

In summary, periodic nanodot arrays have been produced by direct interferometric laser annealing. The magnetic dots are surrounded by either a paramagnetic or a magnetic medium, depending on the employed laser power. This technique and the resulting films have considerable potential for simple fabrication of future magnetic nanostructures and devices.

\section{REFERENCES}

[1] T. A. Savas, M. Farhoud, H. I. Smith, M. Hwang, and C. A. Ross, "Properties of large-area nanomagnet arrays with $100 \mathrm{~nm}$ period made by interferometric lithography," J. Appl. Phys., vol. 85, pp. 6160-6162, Apr. 1999.

[2] A. Fernandez, P. J. Bedrossian, S. L. Baker, S. P. Vernon, and D. R. Kania, "Magnetic force microscopy of single-domain cobalt dots patterned using interference lithography," IEEE Trans. Magn., vol. 32, pp. 4472-4474, Sept. 1996.
[3] J. P. Spallas, R. D. Boyd, J. A. Britten, A. Fernandez, A. M. Hawryluk, J. M. Perry, and D. R. Kania, "Fabrication of sub- $0.5 \mu \mathrm{m}$ diameter cobalt dots on silicon substrates and photoresist pedestals on $50 \mathrm{~cm} \times 50 \mathrm{~cm}$ glass substrates using laser interference lithograph," J. Vac. Sci. Technol. $B$, vol. 14, pp. 2005-2007, May 1996.

[4] B. D. Terris, L. Folks, D. Weller, J. E. E. Baglin, A. J. Kellock, H. Rothuizen, and P. Vettiger, "Ion-beam patterning of magnetic films using stencil masks," Appl. Phys. Lett., vol. 75, pp. 403-405, July 1999.

[5] M. Zheng, M. Yu, R. Skomski, S. H. Liou, D. J. Sellmyer, V. N. Petryakov, Yu. K. Verevkin, N. I. Polushkin, and N. N. Salashchenko, "Magnetic Nanodot Arrays Produced by Direct Laser Interference Lithography," unpublished.

[6] T. Hayashi, S. Hirono, M. Tomita, and S. Umemura, "Magnetic thin films of cobalt nanocrystals encapsulated in graphite-like carbon," $\mathrm{Na}$ ture, vol. 381, pp. 772-774, June 1996.

[7] M. Yu, Y. Liu, and D. J. Sellmyer, "Structural and magnetic properties of nanocomposite Co:C films," J. Appl. Phys., vol. 85, pp. 4319-4321, Apr. 1999.

[8] T. J. Konno and R. Sinclair, "Crystallization of co-sputtered amorphous cobalt-carbon alloys," Acta Metall. Mater., vol. 42, pp. 1231-1247, 1994.

[9] J.-J. Delaunay, T. Hayashi, M. Tomita, and S. Hirono, "Formation and microstructural analysis of co-sputtered thin films consisting of cobalt nanograins embedded in carbon," J. Appl. Phys., vol. 82, pp. 2200-2208, Sept. 1997.

[10] D. Babonneau, J. Briatico, F. Petroff, T. Cabioc'h, and A. Naudon, "Structural and magnetic properties of $\mathrm{Fe}_{2}-\mathrm{C}_{1-x}$, nanocomposite thin films," J. Appl. Phys., vol. 87, pp. 3432-3443, Apr. 2000. 